\title{
Role of Correction Factor in Minimizing Errors While Calculating Electrolyte Values between Blood-gas Analyzer and Laboratory Autoanalyzer: A Comparative Study
}

\author{
Abhinav Banerjee, Gesu Mehrotra \\ Department of Anesthesiology and Critical Care, Tata Main Hospital, Jamshedpur, Jharkhand, India
}

Abstract

\begin{abstract}
Aims: Electrolytes are charged elements that play important functions in the body. They are measured by both arterial blood-gas (ABG) analyzers and autoanalyzers (AA). In this study, we tried to find out the correction factor for sodium and potassium to establish the concordance between ABG and AA values. Materials and Methods: We prospectively studied 100 samples of patients, and for validation of the result, we applied our result on 30 patients later. $1.5 \mathrm{ml}$ of blood collected in the $2.0 \mathrm{ml}$ syringe preflushed with heparin and analyzed using blood-gas analyzer (ABG). Another sample was sent, to central laboratory, where serum $\mathrm{Na}+$ and $\mathrm{K}+$ concentrations were analyzed. Means, standard deviations, and coefficients of variation with Karl Pearson's correlation coefficients were found out. Deming regression analysis was performed and Bland-Altman plots were also constructed. Results: The mean sodium and potassium were $130.27 \pm 7.85 \mathrm{mmol} / \mathrm{L}$ and $3.542 \pm 0.76 \mathrm{mmol} / \mathrm{L}$ using ABG and $139.28 \pm 7.89 \mathrm{mmol} / \mathrm{L}$ and $4.196 \pm 0.72 \mathrm{mmol} / \mathrm{L}$ using AA. Concordance between ABG and AA is done by adding the correction factor: for sodium, correction factor is 9.01 , standard error $=1.113$, class interval $=6.815-11.205$; and for potassium $(\mathrm{K}+)$, correction factor is 0.654 , standard error $=0.1047$, class interval $=0.4475-0.8605$. Conclusion: The instrument type and calibration methods differ in different hospitals, so it is important that each center conducts an in-hospital study to know the correction factor before installation of an ABG, and the factor should be used accordingly to minimize all errors.
\end{abstract}

Keywords: Arterial blood-gas analyzer, autoanalyser, correction factor, serum electrolyte

\section{INTRODUCTION}

Electrolytes are charged elements that are important for various functioning of the body. They play an important role in physiological, biochemical, and metabolic functions such as cell membrane potential generation, neurohormonal pathways coordination, energy generation, and acid-base balance in the body. ${ }^{[1]}$

Almost all metabolic processes are directly coordinated by the electrolytes. Minor-to-major variation in electrolyte values either can be due to a variety of disorders or can also be the cause of multiple complications. They can be acute or chronic and can result in life-threatening problems..$^{[2]}$ Whatever may be the reason ensuring adequate treatment is always required to reverse the metabolic disturbances.

Electrolyte values are measured both by arterial-blood gas (ABG) analyzers and central laboratory autoanalyzers (AA).

\begin{tabular}{|l|l|}
\hline \multicolumn{3}{|c|}{ Access this article online } \\
\hline Quick Response Code: & Website: \\
\hline & www.ijccm.org \\
\hline & \\
\hline
\end{tabular}

In Intensive Care Unit (ICU) setups, intensivist mainly uses the point-of-care measurement of electrolytes by ABG analyzer to combat the time gap and prompt treatment. Typically, a turnaround time of about $2 \mathrm{~h}$ for obtaining the laboratory report is noted on average in acute care laboratories of most tertiary care hospitals in the developing countries. ${ }^{[3]}$

The delay in obtaining the laboratory reports is often because of the delay in transporting samples to the central laboratory, either due to lack of sufficient numbers of human couriers or the absence of rapid transit systems (RTSs). ${ }^{[3]}$

Address for correspondence: Dr. Abhinav Banerjee, Department of Anesthesiology and Critical Care, Tata Main Hospital, Jamshedpur, Jharkhand, India. E-mail: abhinav.banerjee.in@gmail.com

This is an open access article distributed under the terms of the Creative Commons Attribution-NonCommercial-ShareAlike 3.0 License, which allows others to remix, tweak, and build upon the work non-commercially, as long as the author is credited and the new creations are licensed under the identical terms.

For reprints contact: reprints@medknow.com

How to cite this article: Banerjee A, Mehrotra G. Role of correction factor in minimizing errors while calculating electrolyte values between Blood-gas analyzer and laboratory autoanalyzer: A comparative study. Indian J Crit Care Med 2018;22:34-9. 
The technology for detecting the electrolyte assay both of the $\mathrm{ABG}$ and the AA is ion-sensing electrode method. It is used in most of the hospitals. ${ }^{[4]}$ The indirect assay is preanalytical dilution of the sample, sending them to laboratory, and sensing the electrode by flame photometry (the recognized reference method), subsequently finding out the result. ${ }^{[4]}$

In the point-of-care technology, the electrode surface comes in contact with a complete undiluted blood sample and senses the movement of the electrolytes by the ISE technology. Sodium and potassium levels measured in the whole blood and plasma have been shown to be essentially identical. ${ }^{[5]}$ Hence, we assume that the blood and the plasma used for electrolyte measurement in ABG and AA, respectively, should be equal. ${ }^{[6]}$

A lot of studies are published about the comparison of these two methods, and it has been already proved beyond doubt that there remains a highly significant difference statistically in between the electrolytes measured by these two methods. ${ }^{[7,8]}$

In this study, we tried to find out the correction factor for sodium and potassium and then correlating the corrected ABG electrolyte values with the laboratory values.

\section{Materials and Methods}

We have prospectively studied 100 samples of patients hospitalized in ICU from September 2016 to December 2016. The study was approved by the Ethics Committee of the hospital. Arterial blood samples were collected in heparinized blood-gas syringes; $1.5 \mathrm{ml}$ of blood collected in the commercially available plastic $2.0 \mathrm{ml}$ syringe (Dispovan single-use syringe) preflushed with $1 \mathrm{ml}$ of heparin and analyzed using ABL 800 basic blood-gas analyzer immediately which employs direct ISE technology. We take a further sample at the same time, from the same arterial line samples and sent, pneumatically sealed in BD vacutainer serum tube and analyzed within $2 \mathrm{~h}$, to our central laboratory, where serum $\mathrm{Na}+$ and $\mathrm{K}+$ concentrations were analyzed via indirect ISE on a Beckman Coulter AU640 MODEL.

\section{Inclusion criteria}

1. Age between 18 and 70 years

2. Patients whose paired blood samples could simultaneously be collected from an arterial catheter.

\section{Exclusion criteria}

1. Negative informed consent

2. Age under 18 or $>70$ years

3. No arterial catheter

4. Blood samples could not simultaneously be collected.

These samples were collected only when clinically indicated. All samples collected by the specially trained nursing staff.

\section{Analytical precision of sodium and potassium determination}

The blood-gas analyzer is calibrated every 4 hourly with the aid of an in machine calibrator provided by the supplier, in line with daily internal quality control (QC) standards according to the manufacturer's recommendation. An external QC check is performed weekly.

In the laboratory for correct data analysis, we run a two-level QC test every 12 hourly using daily internal QC standards. The central laboratory is accredited to NABL, External Quality Assurance Scheme (EQAS) for quality and standard maintenance.

\section{Statistical methods employed}

Data were evaluated using "MedCalc." Means, standard deviations (SDs), and coefficients of variation were calculated. Karl Pearson's correlation coefficients were found out. Deming regression analysis was performed, and Bland-Altman plots were constructed to compare the results of the two methods. $P<0.0001$ was considered statistically significant.

\section{RESULTS}

The calculation of an adequate sample size becomes crucial in any clinical study. It is the optimum number of participants required to arrive at ethically and scientifically valid results. Generally, the sample size for any study depends on the following acceptable level of significance, power of the study, expected effect of size, underlying event rate in the population, and SD in the population.

We did a pilot study initially to find out the sample size. Taking $\alpha$ at 0.05 and desired power of study is $80 \%$, the sample size needed is 100 .

1. There is statistically no significant difference among the patients according to their gender distribution and age [Tables 1 and 2]

2. The mean sodium concentration was $130.27 \mathrm{mmol} / \mathrm{L} \pm$ SD $7.85 \mathrm{mmol} / \mathrm{L}$ using $\mathrm{ABG}$ and $139.28 \mathrm{mmol} / \mathrm{L} \pm \mathrm{SD}$ $7.89 \mathrm{mmol} / \mathrm{L}$ using the AA [Table 3]

\begin{tabular}{lc}
\hline Table 1: Sex distribution among the patients \\
\hline Gender & Number of patients (\%) \\
\hline Male & $46(46)$ \\
Female & $54(54)$ \\
\hline
\end{tabular}

There is statistically no significant difference among the patients according to their gender distribution, with $P=0.3222(P>0.05)$

Table 2: Age distribution among the patients

\begin{tabular}{lcc}
\hline Age (year) & Male $(\boldsymbol{n = 4 6 )}$ & Female $(\boldsymbol{n = 5 4 )}$ \\
\hline Mean \pm SD & $38.43 \pm 11.59$ & $36.57 \pm 13.45$ \\
\hline There is statistically not significant difference among the patients \\
according to their age distribution in between the two gender, with \\
$P=0.4647(P>0.05)$. SD: Standard deviation
\end{tabular}

Table 3: The mean and standard deviation of sodium level measured by arterial blood gas and laboratory result

\begin{tabular}{lcc}
\hline Level of sodium & In ABG $(\boldsymbol{n = 1 0 0})$ & In laboratory $(\boldsymbol{n = 1 0 0})$ \\
\hline Mean \pm SD & $130.27 \pm 7.85$ & $139.28 \pm 7.89$ \\
\hline \multicolumn{3}{l}{ SD: Standard deviation; ABG: Arterial blood gas }
\end{tabular}


3. The mean potassium concentration was $3.542 \mathrm{mmol} / \mathrm{L} \pm$ SD $0.76 \mathrm{mmol} / \mathrm{L}$ using $\mathrm{ABG}$ and $4.196 \mathrm{mmol} / \mathrm{L} \pm$ SD $0.72 \mathrm{mmol} / \mathrm{L}$ using the AA [Table 4]

4. The extent of inter-analyzer agreement was unacceptable for both $\mathrm{Na}+$ and $\mathrm{K}+$ [Figures 1 and 2]

5. The associated "Karl Pearson's correlation coefficients" of $\mathrm{Na}+$ was $R^{2}=0.9194, r=0.9589$ and of $\mathrm{K}+$ was $R^{2}=0.8615, r=0.9282$, respectively [Figures 3 and 4 ]

6. Deming regression analysis of the ABG and AA data on $\mathrm{Na}+$ levels yielded the following formula: $y=0.9633 x+13.797[$ Figure 4$]$

7. Deming regression analysis of the $\mathrm{ABG}$ and $\mathrm{AA}$

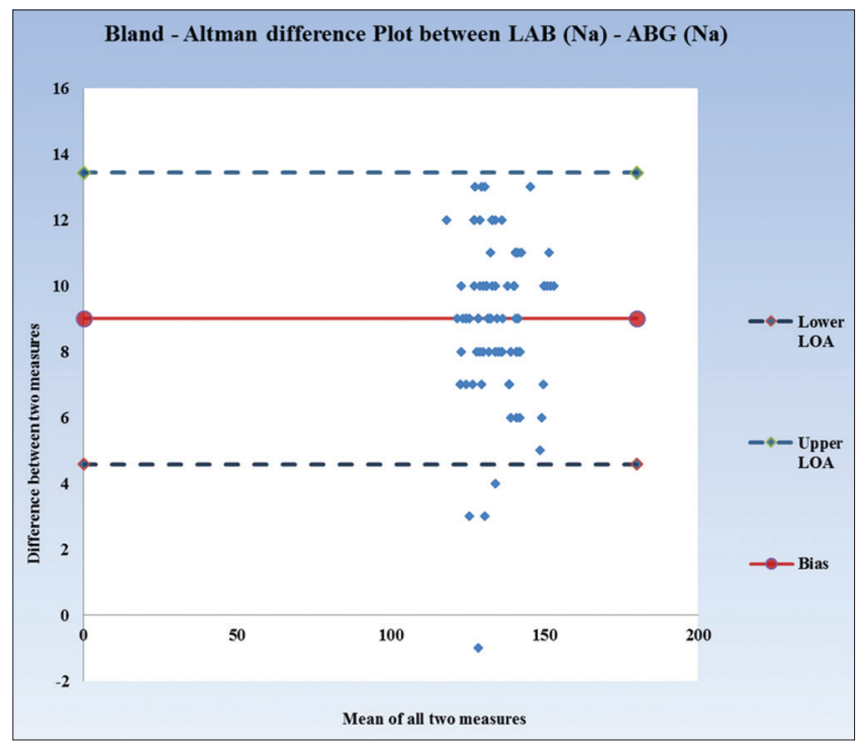

Figure 1: The Bland-Altman difference plot for sodium derived from the arterial blood gas and AA values

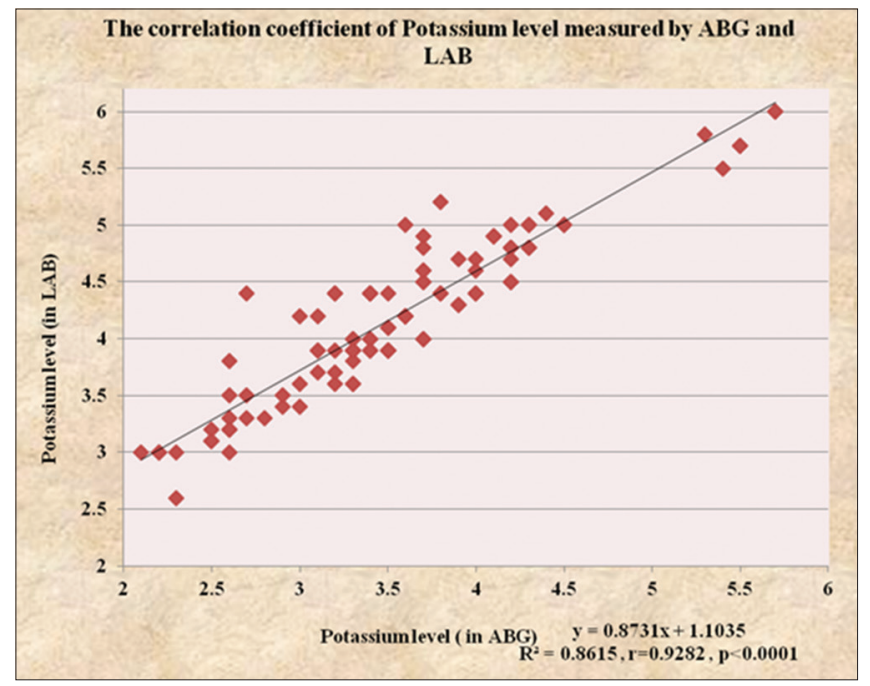

Figure 3: The equation derived from Karl Pearson's correlation coefficient with linear regression analysis was used to potassium level (in arterial blood gas) by potassium level (in laboratory). The line of regression was, $y=0.8731 x+1.1035$ with $R^{2}=0.8615$ and $r=0.9282$ (strongly correlated) data on $\mathrm{K}+$ levels yielded the following formula: $y=0.8731 \mathrm{x}+1.1035$ [Figure 3]

8. We conclude that the $\mathrm{ABG}$ and $\mathrm{AA}$ do not yield equivalent $\mathrm{Na}+$ and $\mathrm{K}+$ data. Concordance between $\mathrm{ABG}$ and $\mathrm{AA}$ should be established the following correction.

- For sodium $(\mathrm{Na}+)$ : The maximum difference is $13 \mathrm{mmol} / \mathrm{L}$ and minimum difference is $1 \mathrm{mmol} / \mathrm{L}$. Mean: $9.01 \mathrm{mmol} / \mathrm{L} \pm 2.25 \mathrm{mmol} / \mathrm{L}$ [Figure 1]

Table 4: The mean and standard deviation of potassium level measured by arterial blood gas and laboratory result

\begin{tabular}{lcc}
\hline Level of potassium & In ABG $(\boldsymbol{n = 1 0 0})$ & In laboratory $(\boldsymbol{n}=\mathbf{1 0 0})$ \\
\hline Mean $\pm \mathrm{SD}$ & $3.542 \pm 0.76$ & $4.196 \pm 0.72$ \\
\hline
\end{tabular}

SD: Standard deviation; ABG: Arterial blood gas

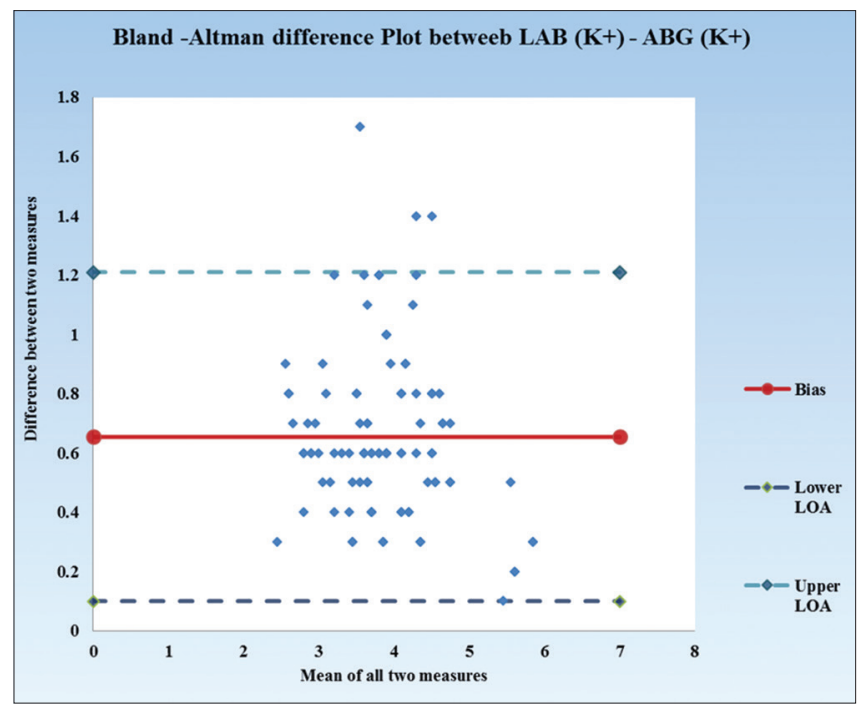

Figure 2: Bland-Altman difference plot for potassium for arterial blood gas and $A A$ values

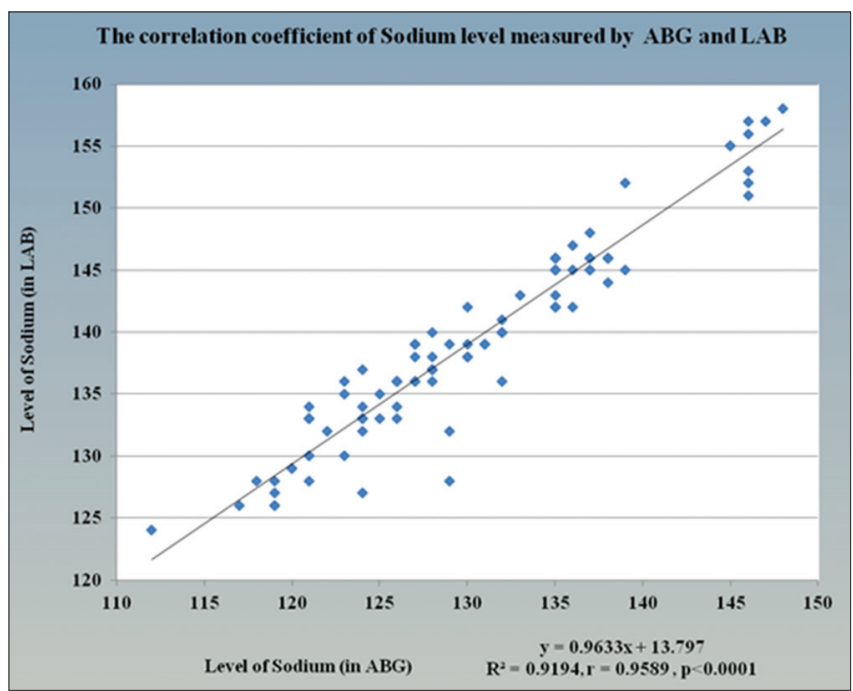

Figure 4: The equation derived from Karl Pearson's correlation coefficient with linear regression analysis was used to sodium level (in arterial blood gas) by Sodium level (in laboratory). The line of regression was, $y=0.9633 x$ +13.797 with $R^{2}=0.9194$ and $r=0.9589$ (strongly correlated) 
Correction factor: current difference $=9.01$, standard error $=1.113,95 \%$ class interval $=6.815-11.205$ considering correction factor with $2 \%-5 \%$ calibration.

- For potassium $(\mathrm{K}+)$ : The maximum difference is $1.7 \mathrm{mmol} / \mathrm{L}$ and minimum difference is $0.1 \mathrm{mmol} / \mathrm{L}$. Mean: $0.654 \mathrm{mmol} / \mathrm{L} \pm 0.28 \mathrm{mmol} / \mathrm{L}$ [Figure 2].

Correction factor: current difference $=0.654$, standard error $=0.1047,95 \%$ class interval $=0.4475-0.8605$ considering correction factor with $2 \%-5 \%$ calibration.

9. The correction factor is then checked for validity.

- Mean \pm SD of potassium in ABG was $3.33 \pm 0.50$ and AA was $4.18 \pm 0.62$ for the next group [Table 5]. The paired $t$-test depicts statistically significant difference. No statistical difference exists when AA is compared with $\mathrm{ABG}$ and correction factor (mean $\pm \mathrm{SD}$ : $4.00 \pm 0.52$ ) taken into account and compared with each other [Table 5]

- Mean $\pm \mathrm{SD}$ of sodium in $\mathrm{ABG}$ was $129.87 \pm 6.90$ and AA was $138.18 \pm 7.73$ for the next group [Table 5]. The paired $t$-test depicts statistically significant difference. No statistical difference exists when AA is compared with $\mathrm{ABG}$ and correction factor (mean $\pm \mathrm{SD}$ : $138.88 \pm 6.91$ ) taken into account and compared with each other [Table 6].

\section{Discussion}

The patients in ICU require more frequent monitoring of the metabolic parameter. Hence, RTS for decreasing the lag time and dedicated laboratory services for emergency and ICU is always required. However, a greater number of hospitals still do not have such high-end facilities. Point-of-care approach of monitoring is done to have rapid bedside result that can help in quick decision and making prompt treatment. ${ }^{[9]}$ The labor costs, reagent cost, and analysis cost are also reduced when compared with the central laboratory analyzing costs. ${ }^{[10]}$

It is known that patients in ICUs are critically ill and tend to have low blood protein levels. The ABG results are not affected by serum protein levels, which make the ABG electrolyte results more accurate for critically ill patients. ${ }^{[11]}$ Moreover, patients can have pseudohyponatremia if protein or cholesterol level is on the rise in ICU patients. Considering using ABG only for evaluating electrolytes can have an high operational cost, but when we consider in total, the amount of information, we get from an ABG, in a critically ill patient such as the oxygen requirement, lactate level, and acidosis per se, the use of ABG machines at critical areas of hospitals such as emergency department, operation theaters, and ICUs are well justified. Furthermore, the direct cost of the machine to the hospital has been on decreasing trend as the supply of such analyzers increases with time. ${ }^{[12]}$

In the study conducted by Morimatsu et al., it was revealed that results with $\mathrm{AA}$ and $\mathrm{ABG}$ differed significantly for

\section{Table 5: The calculated mean and standard deviation of potassium level measured by arterial blood gas and laboratory result after validating correction factor

\begin{tabular}{lccc}
\hline $\begin{array}{l}\text { Level of } \\
\text { Potassium }\end{array}$ & $\begin{array}{c}\text { In ABG } \\
(\boldsymbol{n}=\mathbf{3 0})\end{array}$ & $\begin{array}{c}\text { After addition of correction } \\
\text { factor in ABG }(\boldsymbol{n}=\mathbf{3 0})\end{array}$ & $\begin{array}{c}\text { In laboratory } \\
(\boldsymbol{n}=\mathbf{3 0})\end{array}$ \\
\hline Mean \pm SD & $3.33 \pm 0.50$ & $4.00 \pm 0.52$ & $4.18 \pm 0.62$
\end{tabular} \\ We used paired $|t|$-test and found that there was statistically significant difference among the patients according to their potassium level, with $P$ value $(P<0.0001)$ between original ABG and laboratory values. However, when correction factor is added with the ABG values and compared with the laboratory values. There was statistically no significant difference among the patients according to their potassium level, with $P=0.2280(P>0.05)$. SD: Standard deviation; ABG: Arterial blood gas}

\begin{tabular}{|c|c|c|c|}
\hline $\begin{array}{l}\text { Level of } \\
\text { sodium }\end{array}$ & $\begin{array}{l}\text { In ABG } \\
(n=30)\end{array}$ & $\begin{array}{l}\text { After addition of } \\
\text { correction factor } \\
\text { in ABG }(n=30)\end{array}$ & $\begin{array}{l}\text { In laboratory } \\
\qquad(n=30)\end{array}$ \\
\hline Mean \pm SD & $129.87 \pm 6.90$ & $138.88 \pm 6.91$ & $138.10 \pm 7.73$ \\
\hline \multicolumn{4}{|c|}{$\begin{array}{l}\text { There was statistically significant difference among the patients according } \\
\text { to their sodium level, with } P \text { value }(P<0.0001) \text { between original ABG } \\
\text { and laboratory values. However, when correction factor is added with } \\
\text { the ABG values and compared with the laboratory values. There was } \\
\text { statistically no significant difference among the patients according to their } \\
\text { sodium level, with } P=0.6818(P>0.05) \text {. SD: Standard deviation; ABG: } \\
\text { Arterial blood gas }\end{array}$} \\
\hline
\end{tabular}

the plasma sodium and chloride levels. The mean plasma sodium concentration was $140.4 \pm 5.6 \mathrm{mmol} / \mathrm{L}$ with central laboratory testing versus $138.3 \pm 5.9 \mathrm{mmol} / \mathrm{l}$ with point-of-care testing $(P<0.0001)$. The mean plasma chloride concentration was $102.4 \pm 6.5 \mathrm{mmol} / \mathrm{L}$ versus $103.4 \pm 6.0 \mathrm{mmol} / \mathrm{L}$ $(P<0.0001){ }^{[13]}$

Furthermore, Chacko et al. also concluded that the differences in the measured sodium levels between the two methods were significant. There was a significant difference in the mean $\pm \mathrm{SD}$ of sodium value between whole blood and serum samples, $135.8 \pm 5.7 \mathrm{mmol} / \mathrm{L}$ versus $139.9 \pm 5.4 \mathrm{mmol} / \mathrm{L}$ $(P<0.001)$. Although the agreement between whole blood and serum potassium was good, and the average difference was small, still the individual differences were clinically significant, particularly at lower potassium values. ${ }^{[7]}$

Consistent with the literature, our study also found a significant difference between the two methods for analysis of sodium and potassium levels. Thus, making clinical decisions for sodium and potassium according to $\mathrm{ABG}$ seems unreliable. The mean sodium concentration was $130.27 \mathrm{mmol} / \mathrm{L} \pm \mathrm{SD} 7.85 \mathrm{mmol} / \mathrm{L}$ using $\mathrm{ABG}$ and $139.28 \mathrm{mmol} / \mathrm{L} \pm \mathrm{SD} 7.89 \mathrm{mmol} / \mathrm{L}$ using the AA [Table 3]. The mean potassium concentration was $3.542 \mathrm{mmol} / \mathrm{L} \pm \mathrm{SD} 0.76 \mathrm{mmol} / \mathrm{L}$ using $\mathrm{ABG}$ and $4.196 \mathrm{mmol} / \mathrm{L} \pm \mathrm{SD} 0.72 \mathrm{mmol} / \mathrm{L}$ using the AA[Table 4]. These differences do significantly affect the calculation of the anion gap values and can lead physicians to different assessments of the acid-base and electrolyte levels. 
Foremost, each instrument uses a different sample; autoanalyzer (AA) uses serum and ABG uses whole blood. Actually electrolyte analysis should be performed on serum, which is the portion of blood without cells or clotting factors. Serum has no contribution that hemolyzed cells might make to the sample. Among electrolytes, potassium, in particular, is stored primarily within the cell; this presents a problem in analyzing whole-blood samples that can undergo hemolysis, which releases potassium from the cell and can cause a falsely elevated value. Factors that can cause hemolysis in a sample include small needle size, rough handling, incorrect temperature, and elapsed time. It mainly occurs due to prolonged storage at low temperatures or prolonged time between sampling and analysis..$^{[1,15]}$ Although Flegar-Mestrić and Perkov debated on the fact that $\mathrm{K}$ levels measured in whole blood and plasma have been shown to be essentially same ${ }^{[16]}$ and the release of $\mathrm{K}$ from platelets during clotting may cause statistically insignificant increase of levels in serum. ${ }^{[6]}$

The above reason can lead to overestimation of potassium or other intercellular electrolytes in the ABG sample as whole blood is used for the test which was not evident in our study.

However, some studies projected the fact that overestimation or erroneous result is actually from the laboratory and is of the indirect ISE values. They brought the fact that the measurement is clearly linked to serum protein and albumin levels. Story et al. have reported that indirect ISE leads to overestimation of $\mathrm{Na}$ in hypoalbuminemia. The difference between direct and indirect ISE results was found to correlate with serum albumin and total protein concentrations. ${ }^{[17,18]}$

Other reasons can be dilution with flush fluid when sampling from a catheter. Or different heparin volumes in ABG sampling syringes dilute the whole blood and lower the levels of measured electrolytes in ABG testing. ${ }^{[19]}$ The heparin being negatively charged also binds with the electrolytes, thereby lowering its value by decreasing their movement which is actually the technology of their detection. ${ }^{[20,21]}$ Thus, we strongly agree with Chow et al., who reported that direct ISE sodium and potassium figures were lower than those obtained using indirect ISE. ${ }^{[18]}$

The wide variability, as shown in the Bland-Altman plots, and the statistically significant mean differences in measured electrolyte levels between the two analyzers suggest that the tests do not yield equivalent data. As our laboratory is accredited to EQAS for quality and standard maintenance, we keep on checking the sample with multiple external laboratory data. Hence, we consider it as reference value for all our measurements and treatments.

Taking things one step forward to compensate the variation, we tried to find a correction factor and then add it up with the $A B G$ value for appropriation of the ABG value with the AA. The question is whether such compensation is appropriate. Rouse in his study first talked about this concept and usage of a correction factor may minimize the differences between the analyzing instruments. ${ }^{[22]}$

We found out that the concordance between $\mathrm{ABG}$ and $\mathrm{AA}$ can be established for sodium by correction factor of $9.01 \mathrm{mmol} / \mathrm{L}$ [Figure 1] and for potassium $(\mathrm{K}+)$ correction factor of $0.654 \mathrm{mmol} / \mathrm{L}$ [Figure 2]. We validated the appropriate use of it by taking 30 patients' ABG electrolyte values from January 2017 to March 2017 and adding the correction factor to it and then correlating it to their respective AA values. The results showed were statistically nonsignificant.

The limitations of our study are use of one AA and one ABG machine and the ABG samples were collected using conventional syringes containing liquid heparin. The use of dried heparin syringes could improve the accuracy of the results by decreasing the dilution of the sample.

\section{Conclusion}

The correction factor should be determined individually for each hospital. It is important for each center to perform its own studies with regard to concordance. As instrument type and calibration methods may differ among hospitals, it is important that each center conduct an in-hospital study ideally before installation of an $\mathrm{ABG}$, and both the instruments should be calibrated accordingly.

\section{Financial support and sponsorship}

Nil.

\section{Conflicts of interest}

There are no conflicts of interest.

\section{RefEREnCes}

1. Hoekstra M, Vogelzang M, Drost JT, Janse M, Loef BG, van der Horst IC, et al. Implementation and evaluation of a nurse-centered computerized potassium regulation protocol in the Intensive Care Unit - A before and after analysis. BMC Med Inform Decis Mak 2010;10:5.

2. Murray MJ, James M. American Society of Critical Care Anesthesiologists. Philadelphia, PA: Lippincott Williams \& Wilkins; 2002. p. 168-9.

3. Cox CJ. Acute care testing. Blood gases and electrolytes at the point of care. Clin Lab Med 2001;21:321-35.

4. Scott MG, LeGrys VA, Klutts JS. Electrolytes and blood gases. In: Burtis DE, Ashwood ER, Bruns DE, editors. Tietz Textbook of Clinical Chemistry and Molecular Diagnostics. $4^{\text {th }}$ ed. St. Louis, MO: Elsevier; 2006. p. 983-1018.

5. D’Orazio P, Miller WG, Myers GL, Doumas BT, Eckfeldt JH, Evans SA, et al. Standardization of Sodium and Potassium Ion-Selective Electrode Systems to the Flame Photometric Reference Method: Approved Standard. C29-A2. $2^{\text {nd }}$ ed., Vol. 20. CLSI; 2000. p. 1-22.

6. Ladenson JH. Direct potentiometric measurement of sodium and potassium in whole blood. Clin Chem 1977;23:1912-6.

7. Budak YU, Huysal K, Polat M. Use of a blood gas analyzer and a laboratory autoanalyzer in routine practice to measure electrolytes in intensive care unit patients. BMC Anesthesiol 2012;12:17.

8. Chacko B, Peter JV, Patole S, Fleming JJ, Selvakumar R. Authors' reply. Indian J Crit Care Med 2011;15:196-7.

9. Burtis C, Bruns D, editors. Tietz Fundamentals of Clinical Chemistry and Molecular Diagnostics. $7^{\text {th }}$ ed. Philadelphia PA: Saunders; 2014.

10. Statland BE, Brzys K. Evaluating STAT testing alternatives by calculating annual laboratory costs. Chest 1990;97:198S-203S. 
11. King RI, Mackay RJ, Florkowski CM, Lynn AM. Electrolytes in sick neonates - Which sodium is the right answer? Arch Dis Child Fetal Neonatal Ed 2013;98:F74-6.

12. Magny E, Beaudeux JL, Launay JM. Point care testing in blood gas and electrolyte analysis: Examples of implementation and cost analysis. Ann Biol Clin (Paris) 2003;61:344-51.

13. Morimatsu H, Rocktäschel J, Bellomo R, Uchino S, Goldsmith D, Gutteridge G, et al. Comparison of point-of-care versus central laboratory measurement of electrolyte concentrations on calculations of the anion gap and the strong ion difference. Anesthesiology 2003;98:1077-84.

14. Scott MG, LeGrys VA, Klufts JC. Electrolytes and blood gases. In: Burtis CA, Ashwood E, Bruns DE, editors. Tietz Textbook of Clinical Chemistry. $4^{\text {th }}$ ed., Ch. 27. Missouri USA: Elsevier; 2006. p. 985.

15. Sakyi A, Laing E, Ephraim R, Asibey O, Sadique O. Evaluation of analytical errors in a clinical chemistry laboratory: A 3 year experience. Ann Med Health Sci Res 2015;5:8-12.

16. Flegar-Mestrić Z, Perkov S. Comparability of point-of-care whole-blood electrolyte and substrate testing using a stat profile critical care xpress analyzer and standard laboratory methods. Clin Chem Lab Med 2006;44:898-903.

17. Story DA, Morimatsu H, Egi M, Bellomo R. The effect of albumin concentration on plasma sodium and chloride measurements in critically ill patients. Anesth Analg 2007;104:893-7.

18. Chow E, Fox N, Gama R. Effect of low serum total protein on sodium and potassium measurement by ion-selective electrodes in critically ill patients. Br J Biomed Sci 2008;65:128-31.

19. Jacobs E, Ancy JJ, Smith M. Multi site performance evaluation of $\mathrm{pH}$, bood gas, electrolyte, glucose and lactate determinations with the GEM Premier 3000 critical care analyser. Point Care 2002;1:135-44.

20. van Berkel M, Scharnhorst V. Electrolyte-balanced heparin in blood gas syringes can introduce a significant bias in the measurement of positively charged electrolytes. Clin Chem Lab Med 2011;49:249-52.

21. Yilmaz S, Uysal HB, Avcil M, Yilmaz M, Dağlı B, Bakış M, et al. Comparison of different methods for measurement of electrolytes in patients admitted to the Intensive Care Unit. Saudi Med J 2016;37:262-7.

22. Rouse C. Theoretical reasons for sodium measurement error - POCT specialist -C29-A2 ISBN 1-56238-410-4 ISSN 0273-3099. 